\title{
0 consumo cultural-digital das famílias brasileiras
}

\author{
Elder Patrick Maia Alves * \\ Bruno Gontyjo do Couto**
}

\section{Resumo}

Este trabalho tem como objeto a expansão do consumo cultural-digital das famílias brasileiras nos últimos dez anos. Tal expansão implicou diretamente a elevação de seus gastos orçamentários com cultura. De acordo com o IBGE, em 2009, as famílias brasileiras dispenderam em média $5 \%$ do seu orçamento mensal com bens culturais. Caso os serviços de telefonia e comunicação fossem adicionados à rubrica cultura, essa mesma média de gastos saltaria para 8,6\%. Em face do aumento da produção, distribuição e consumo dos serviços culturais-digitais (séries, filmes, músicas, games, etc.) por meio dos dispositivos digitais móveis, notadamente os smartphones, sustentamos que a metodologia de cálculo e aferição do IBGE exige uma revisão. Para sustentar tal necessidade, demonstramos que os mercados culturais passam por uma profunda mudança: a digitalização do simbólico.

\section{Palavras-chave}

Consumo cultural-digital. Orçamento das famílias. Digitalização do simbólico.

\section{Abstract}

This article's object of study is the expansion of the digital-cultural consumption in Brazilian families in the last ten years. This expansion directly implied on the rise of Brazilian families' expenses with culture. According to IBGE, in 2009, Brazilian families dispended an average of $5 \%$ of their monthly budget with cultural goods. If telecommunication services were included in the culture category, this average would increase to $8,6 \%$. Considering the expansion of the production, distribution and consumption of digital-cultural services (TV shows, films, music, games, etc.), through the use of digital devices, namely smartphones, we believe that the calculation and gauging methodology used by IBGE should be revised. To support this requirement, we demonstrate that cultural markets are going through a profound change: the "digitalization of the symbolic".

\section{Keywords}

Cultural-digital Consume. Families budget. Digitalization of the Symbolic.

\footnotetext{
* Elder Patrick Maia Alves é Professor Adjunto do Instituto de Ciências Sociais (ICS) da Universidade Federal de Alagoas (UFAL) e professor do Programa de Pós-Graduação em Sociologia (PPGS-UFAL). Doutor em Sociologia pela Universidade de Brasília (UnB). E-mail: epmaia@hotmail.com.

** Bruno Gontyjo do Couto é doutorando no Programa de Pós-Graduação em Sociologia da Universidade de Brasília (UnB). E-mail: brunogcouto@gmail.com.
} 


\section{Introdução}

Nos trabalhos que temos publicados ao longo dos últimos três anos, defendemos a tese de que os mercados culturais globais estão experimentando um intenso processo de digitalização do simbólico (ALVES, 2016, 2017). Esse processo ganhou terreno à medida que quatro fenômenos conjugados assumiram regularidade global: 1) a consolidação do processo de integração digital, ancorado na condensação de diferentes linguagens, mídias e tecnologias em um único suporte, o telefone celular móvel - o smartphone; 2) a ampliação vertiginosa do uso desse mesmo suporte digital móvel; 3) o advento dos modelos de negócios ancorados na tecnologia de streaming, que consiste na compra de conteúdo on-line (livros, filmes, séries, games, músicas, etc.) mediante o pagamento regular de mensalidades, cuja consolidação somente passou a existir através do intenso aumento da velocidade da internet e do advento da computação em nuvem, que torna possível o armazenamento e a transmissão instantânea de conteúdos; 4) a difusão da chamada internet 2.0, fase de expansão da internet, na qual os próprios usuários produzem, distribuem e consomem a maioria dos conteúdos criados (notícias, imagens, textos, vídeos, etc.).

Esses quatro fenômenos compõem um quadro histórico que evidencia que o consumo simbólico-cultural caminha cada vez mais para a prática de fruição dos serviços culturais-digitais: compra de conteúdos de arte, cultura e entretenimento ofertados por meio de plataformas digitais especializadas das principais companhias globais de tecnologia digital, como Google, Facebook, Amazon, Apple, Microsoft, Netflix, Deezer e Spotify. Uma mudança nas práticas de consumo que tem impactado diretamente a estrutura dos orçamentos familiares destinados à cultura.

Em outra oportunidade (ALVES, 2019), utilizamos esse argumento para demonstrar as lacunas da metodologia utilizada há quase uma década pelo Instituto Brasileiro de Geografia e Estatística (IBGE). Em 2009, o IBGE calculou os gastos orçamentares médios das famílias brasileiras com cultura, chegando-se ao percentual de 5,0\%. Significa que, àquela altura, as famílias brasileiras gastavam $5,0 \%$ do seu orçamento mensal com atividades, bens e serviços culturais (IBGE, 2011). Na ocasião, o IBGE advertiu que, caso os serviços de comunicação fossem inseridos nesse cálculo, os dispêndios orçamentários das famílias brasileiras com cultura alcançariam 8,6\% do seu orçamento. Ora, tendo em vista que os dispositivos digitais móveis (especialmente os smartphones) têm se tornado cada vez mais unidades 
de consumo de conteúdos de arte, cultura e entretenimento, e muito menos aparelhos utilizados para práticas de comunicação mediadas, como as chamadas telefônicas, então se justifica a inserção dos serviços de comunicação no cômputo dos dispêndios orçamentários com cultura no Brasil e no mundo.

Mas será que essa assertiva pode ser sustentada mediante a depuração de diferentes fontes de dados que, em conjunto, sugeririam a adoção de uma nova metodologia de cálculo? E por que as famílias figuram no centro dessa hipótese?

As famílias figuram no centro dessa hipótese porque ocupam o centro dinâmico dos mercados culturais, que estão se tornando, cada vez mais, mercados culturais-digitais ${ }^{1}$. Neste trabalho, objetivaremos um único mercado cultural, justamente o maior, mais complexo, diferenciado e globalizado: o mercado audiovisual. Esse mercado é composto por seis vetores distintos: 1) vídeo doméstico (CD, DVD, Blue-Rey); 2) TV aberta; 3) TV por assinatura; 4) internet (contendo variados suportes); 5) games (contendo oito ecossistemas); e 6) cinema de tela grande (cinema de shopping). Mais especificamente, analisaremos o consumo que as famílias brasileiras estabelecem em três desses setores: internet, TV fechada e cinema de shopping. A partir dessa análise, o trabalho colocará à prova a hipótese apresentada e a recomendação que a acompanha: é preciso incorporar, nos cálculos das contas nacionais acerca do consumo das famílias e dos seus gastos orçamentares com cultura, os serviços culturais-digitais.

Para tal, essa investigação lança mão de oito fontes de dados: 1) os dados sobre a migração dos conteúdos culturais para os serviços digitais, especialmente os coletados junto às companhias e operadoras de telefonia móvel; 2) o anuário estatístico do cinema brasileiro, produzido pela Agência Nacional de Cinema (ANCINE); 3) o informe preliminar anual de 2017 sobre o cinema brasileiro, também produzido pela ANCINE; 4) o estudo anual sobre o emprego no setor audiovisual, também produzido pela ANCINE; 5) o estudo sobre o impacto da crise econômica nos mercados de programação e empacotamento da TV por assinatura no Brasil, produzido pela ANCINE; 6) a pesquisa nacional por amostras de domicílios acerca do acesso à internet, à televisão e posse de telefone móvel celular para uso pessoal (IBGE, 2017a);

\footnotetext{
${ }^{1}$ Os mercados culturais são compostos por seis agentes socioeconômicos estruturais. São eles: 1) as empresas culturais privadas especializadas; 2) os trabalhadores e profissionais da cultura; 3) as organizações e instituições governamentais e estatais; 4) os bancos comerciais privados; 5) as corporações não culturais; e 6) os consumidores e fruidores (famílias e indivíduos).
} 
7) a pesquisa cultura e tecnologias no Brasil, produzida pela Organização das Nações Unidas para Ciência, Educação e Cultura (UNESCO), através do Centro Regional de Estudos para o Desenvolvimento da Sociedade da Informação (CETIC.BR); 8) a pesquisa nacional sobre consumo de mídia e tempo livre, produzida pela Secretaria de Comunicação da Presidência da República. Esses bancos de dados abarcam uma série histórica de dez anos, entre 2007 e $2017^{2}$.

\section{A aproximação entre cultura e economia no capitalismo pós-industrial}

Muitos autores das Ciências Sociais têm defendido que, nos últimos 30 anos, a aproximação estrutural entre as esferas da cultura e da economia produziu uma nova configuração histórico-social. Como Walter Benjamin já havia assinalado, essas duas esferas não estavam totalmente apartadas, de modo que as mediações entre arte, técnica e mercado já estavam presentes nos séculos XIX e XX (BENJAMIN, 2007). Entretanto, toda a visão de mundo das sociedades modernas - e, logo, seu modo de funcionamento esteve fundada na perspectiva de que havia uma separação e diferenciação fundamental entre esses dois domínios. Assim, à medida que essa separação/diferenciação passa a ser colocada em cheque com as profundas mudanças que o modelo socioeconômico capitalista sofre nos anos 1970 e 1980, todo um debate teórico e empírico é deflagrado com o intuito de traduzir as novas mediações entre as esferas da cultura e da economia.

Desse modo, recorremos às contribuições de sociólogos que desenvolveram trabalhos importantes ainda nas décadas de 1970 e 1980 com o objetivo de dar conta desse novo contexto. Em sua análise pioneira, Daniel Bell (1977) constata que, no transcorrer dos anos de 1970 e 1980, o processo de desindustrialização das principais economias do globo vinha se acentuando drasticamente. A partir dessa constatação, Bell argumenta que

\footnotetext{
${ }^{2}$ Para testar a hipótese de que há um processo marcante de expansão do consumo dos serviços culturais-digitais no Brasil e que, assim, deveria ser incorporado no cálculo dos gastos orçamentares das famílias brasileiras, o presente trabalho lança mão de diferentes pesquisas de cunho estatístico desenvolvidas pela ANCINE, IBGE, dentre outros, com o objetivo de sublinhar tendências e fenômenos empíricos relativos à realidade brasileira que convergem no sentido do argumento levantado. Assim, é importante destacar que essas pesquisas possuem especificidades metodológicas e recortes próprios, não sendo parte de um mesmo esforço. Para os fins deste trabalho, cada uma delas foi devidamente analisada em separado e quaisquer informações aqui aproveitadas encontram-se diretamente referenciadas à fonte original.
} 
um novo modelo socioeconômico, batizado por ele como "capitalismo pósindustrial", estaria se constituindo, de modo que o vertiginoso crescimento do "setor terciário" acabaria por torná-lo mais importante do que a própria indústria, consagrando-se como principal fundamento tanto da estrutura ocupacional quanto da geração de valor agregado nas maiores economias do mundo (BELL, 1977). A partir do século XXI, o fenômeno aludido já pôde ser constatado nas reduções da participação do setor industrial na composição do Produto Interno Bruto (PIB) das principais economias do mundo, inclusive nas séries históricas de países como o Brasil.

Por outro lado, o próprio Bell e outros autores como Manuel Castells, Scott Lash e Anthony Giddens chamaram a atenção para o processo simultâneo de consolidação das chamadas "economias do conhecimento". Como parte de suas reflexões, Daniel Bell chega à conclusão de que os "eixos de produção" e as "formas de conhecimento" das sociedades pósindustriais estavam fundamentalmente vinculados "à codificação do conhecimento em sistemas abstratos de símbolos que, como em qualquer sistema axiomático, pudessem ser utilizados para iluminar áreas variadas e múltiplas da experiência" (BELL, 1977, p.12). Entretanto, não haveria a consolidação da economia do conhecimento na década de 1990 sem a profusão dos serviços de comunicação, informação e entretenimento. Assim, como demonstrado por Castells na trilogia da sociedade em rede, durante as décadas de 1960 e 1970, houve um investimento maciço por parte dos governos das mais poderosas economias do globo em atividades de pesquisa e desenvolvimento que pudessem resultar em ganhos de valor econômico e de competitividade (CASTELLS, 2010). O resultado foi a construção dos principais sistemas nacionais de inovação tecnológica do mundo, responsáveis pelo desenvolvimento das tecnologias de comunicação, informação, semicondutores, computadores, dentre outros aparelhos, que transformaram toda a base material e logística da estrutura econômica global. A partir daí, pavimentou-se o caminho para que o conhecimento se tornasse o principal ativo gerador de valor no capitalismo (CASTELLS, 2010).

Esses dois processos simultâneos, a expansão das sociedades pósindustriais de serviços e a consolidação das economias do conhecimento, foram determinantes para a aproximação estrutural entre o domínio estético-simbólico e o domínio econômico-tecnológico que vem ocorrendo pelo menos nos últimos 30 anos. Mais do que isso, eles criaram as condições de possibilidade para deflagração dos processos que aqui nos interessa 
descrever: a digitalização e a expansão global dos mercados culturais - o que nos nossos trabalhos temos designado como a "digitalização do simbólico" (ALVES, 2016; ALVES, 2017; ALVES, 2019).

O fenômeno da "digitalização do simbólico" está lastreado em quatro tendências históricas: i) a intensa elevação do aumento da velocidade, capacidade de armazenamento e transmissão de dados por parte da rede mundial de computadores, potencializada por meio da tecnologia do streaming e da computação em nuvem; ii) a profusão global dos dispositivos digitais móveis (notadamente os smartphones), fabricados por grandes corporações globais como Apple e Samsung; iii) a convergência digital, que conecta diversos dispositivos entre si, múltiplos suportes e linguagens, permitindo o fenômeno transmídia e multitela; iv) e o advento da internet 2.0, etapa da internet por meio da qual a grande maioria dos conteúdos e dados (textos, notícias, vídeos, músicas, mensagens, imagens, etc.) são criados, compartilhados e consumidos pelos próprios usuários, engajados nas principais redes sociais digitais do planeta, como Facebook, Instagram, WhatsApp, Youtube e Twitter. Essas quatro tendências conjugadas penetraram paulatinamente os mercados culturais, redimensionando o processo de criação, produção, distribuição e consumo dos conteúdos artístico-culturais, como livros, músicas, filmes e fotografias. Pouco a pouco, houve uma intensa migração dos conteúdos que caracterizam os bens culturais para os chamados serviços culturais-digitais.

\section{A digitalização do simbólico e os gastos das famílias}

O processo de digitalização do simbólico e as suas diversas interfaces tecnológicas, criativas, corporativas e econômicas correspondem, por sua vez, à condição de possibilidade para a expansão e consolidação do que em outra oportunidade batizamos de capitalismo cultural-digital (ALVES, 2017). O capitalismo cultural-digital é composto por diversos mercados culturais-digitais globais, interdependentes e concorrentes entre si. 
Figura 1 - Composição do capitalismo cultural-digital

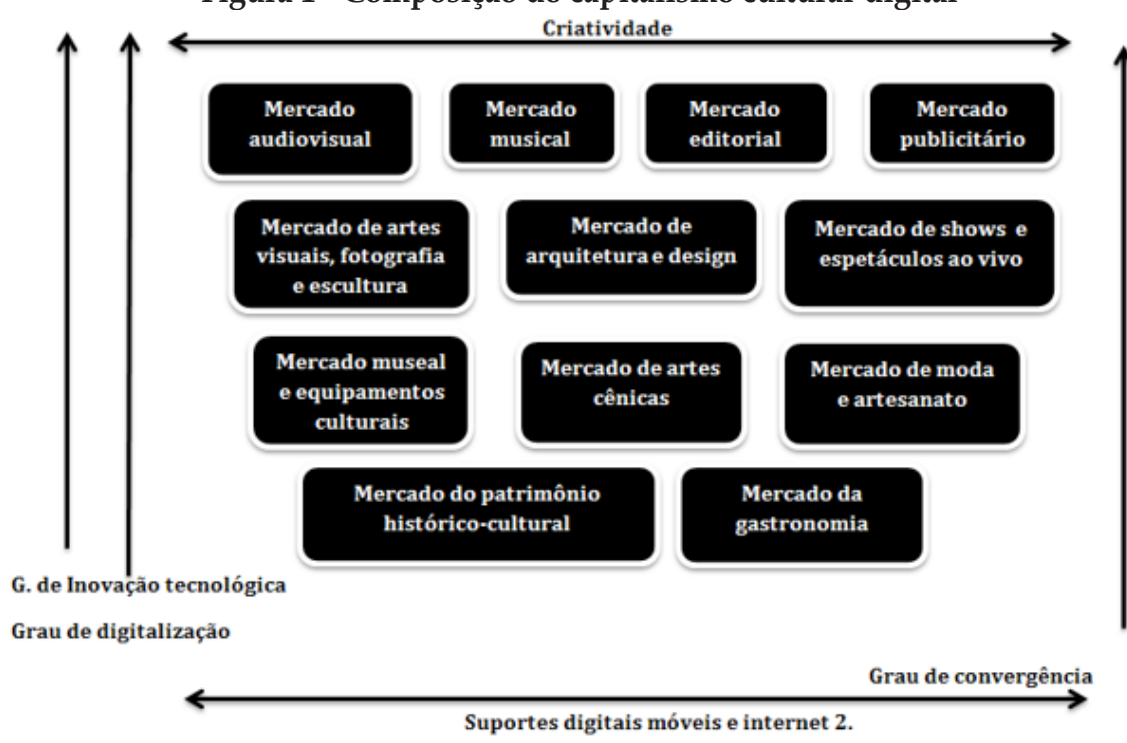

Fonte: Elaboração dos autores.

Há três aspectos estruturais que diferenciam os mercados culturaisdigitais contemporâneos: i) o grau de inovação tecnológica; ii) o grau de digitalização; e iii) o grau de convergência digital. Cada mercado possui estágios muito distintos de digitalização. Os quatro mercados culturaisdigitais, localizados no topo da Figura 1 (audiovisual, musical, editorial e publicitário), são os que possuem o maior grau de inovação tecnológica, maior grau de digitalização e o maior grau de convergência digital. Significa dizer que são os mercados que estão passando por uma intensa transição digital e, por conseguinte, de maior penetração dos serviços culturais-digitais. Os serviços culturais estão diretamente vinculados aos fluxos digitais e ao processo de desmaterialização, assim definido pela UNESCO. A desmaterialização consiste na digitalização dos conteúdos, principalmente os cinematográficos, musicais, editoriais e os jogos digitais. O conteúdo de um filme consumido em uma sala de cinema em um shopping center é classificado como o consumo de um bem cultural. Já a fruição desse mesmo filme nos dispositivos digitais móveis e fixos passa a constituir o consumo de um serviço cultural.

A expansão dos serviços culturais potencializou a geração de negócios antes inexistentes há cinco anos. São negócios cujas condições de possibilidades surgiram em meio ao processo de digitalização do simbólico 
e integração do capitalismo cultural-digital, no interior do qual as maiores companhias de tecnologia passaram a operar como produtoras, licenciadoras e distribuidoras de conteúdos artísticos, culturais e de entretenimento. Uma das empresas mais cobiçadas do mundo, a empresa norte-americana Netflix, possuía, no primeiro trimestre de 2018, 125 milhões de assinantes em todo o mundo, tornando-a a empresa de mídia mais valiosa do planeta, com valor de mercado de US $\$ 172$ bilhões, ao passo que a Disney, segunda maior empresa de mídia do globo, estava avaliada em US\$ 162 bilhões. A compra da Fox pela Disney, em dezembro de 2017, exemplifica bem a força econômica dos serviços culturais-digitais, bem como a definição de novas estratégias e racionalidades empresariais no âmbito do capitalismo culturaldigital. A Disney comprou a Fox por US $\$ 54,6$ bilhões, passando a controlar uma miríade de conteúdos de séries, filmes, documentários e animações, como as séries Os vingadores, X-Men, entre outros. Com a aquisição da Fox, a Disney passou a controlar $70 \%$ do principal concorrente direto da Netflix nos Estados Unidos, o serviço de steamming Hulu, que, no final de 2017, já possuía 20 milhões de assinantes pagos fixos. Com a aquisição, a Disney anunciou que pretende oferecer o serviço da Hulu em todo o mundo em 2019.

A receita operacional líquida da Netflix, em 2014, foi de US\$ 5.5 bilhões; em 2010, quatro anos antes, foi de US\$ 2.2 bilhões. Em 2014, a principal concorrente direta da Netflix, a Amazon Vídeo (com 60 milhões de assinantes mundo afora), anunciou um plano de expansão para mais de 200 países. Já o Spotify possuía, no final de 2017, uma carteira com mais de 50 milhões de assinantes, bem à frente do seu concorrente direto, a Apple Music, que amealhava cerca de 15 milhões de assinantes (DEEZER, 2017). O conjunto das exportações dessas companhias tornou os Estados Unidos o maior exportador de bens culturais-digitais do globo, cujo valor total, US\$ 68,6 bilhões, em 2012, foi superior ao somatório de todos os 14 maiores exportadores juntos. Os ativos financeiros (ações e receitas líquidas) das cinco maiores companhias de internet do mundo - Google, Facebook, Amazon, Apple e Microsoft - já eram suficientes, em 2013, para a aquisição dos sete maiores estúdios cinematográficos de Hollywood juntos (VOGELSTEIN, 2014). No primeiro semestre de 2018, as companhias de tecnologia e também, agora, de entretenimento, arte e cultura, que compõem a sigla GAFAM (MARTEL, 2013) - Google, Amazon, Facebook, Apple e Microsoft -, eram as principais corporações em valor de mercado do mundo. 


\section{0 vetor cinema}

Em 2014, o consumo das famílias brasileiras apresentou um crescimento moderado de $1,6 \%$. No ano seguinte, houve uma contração bastante acentuada: - 4\%. Em 2016, o recuo foi ainda maior, $-4,3 \%$, acumulando uma redução de - 8,3\%. Em 2014, o Produto Interno Bruto per capita (PIB per capita) registrou uma queda de $-0,4 \%$. De acordo com o IBGE, nos anos seguintes, 2015 e 2016, o PIB per capita registrou um recuo de $-8,5 \%$. O consumo das famílias no Brasil apresentou um declínio em toda a cesta regular de produtos, como alimentação, vestuário, transporte, moradia, etc. Mas será que o mesmo ocorreu com os bens, serviços e atividades culturais? Para responder a tal pergunta, selecionamos justamente o mercado culturaldigital que dispõe do maior acervo de dados consolidados, especialmente os três vetores que mais têm impacto nos orçamentos familiares, o vetor internet, o vetor TV por assinatura e o vetor cinema de shopping.

Gráfico 1 - Consumo das famílias no Brasil (2003-2014)

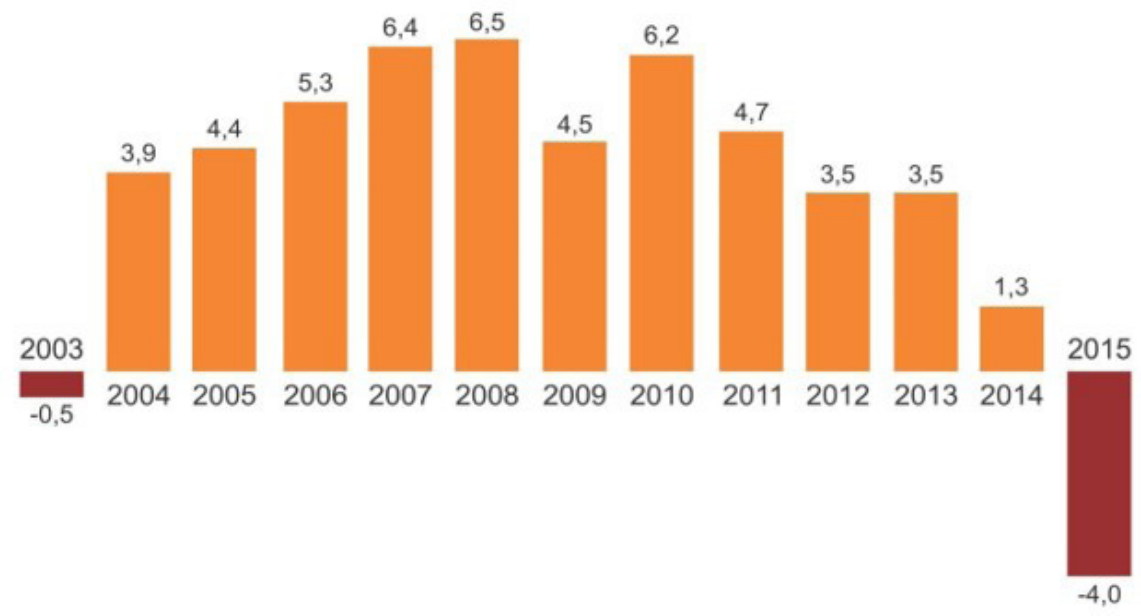

Fonte: IBGE (2017a).

Embora o consumo das famílias e a renda per capita tenham registrado acentuadas quedas nos anos de 2014, 2015 e 2016, esses foram justamente os anos em que se constataram os maiores crescimentos na venda de ingressos para os cinemas brasileiros, que saiu de 155,6 milhões de ingressos vendidos, em 2014, para 173 milhões de ingressos comercializados em 2015, um crescimento de 17,4 milhões de ingressos em apenas um ano, o 
que significou uma elevação de 11\%. Em 2016, o crescimento continuou, alcançando 184,3 milhões de ingressos vendidos. Embora em 2017 tenha ocorrido uma leve queda na comercialização de ingressos, recuando para 181,2 milhões (redução de 1,7\%), essa redução ainda demonstra pouco impacto diante do acentuado arrefecimento constatado nos demais itens de consumo das famílias brasileiras.

Se o mercado do audiovisual é o maior e mais lucrativo mercado cultural do mundo, o vetor cinema de tela grande é o vértice que atrai o maior número de negócios e consumidores.

Entre 2007 e 2017, o vetor do cinema de tela grande experimentou um crescimento exponencial no Brasil, posicionando o país como sexto principal mercado de cinema de tela grande do mundo. Em 1997, o Brasil possuía 1.033 salas de cinema, em 2017 eram 3.220, crescimento de mais de $200 \%$ em vinte anos. Do total de salas em 2017, 88,9\% estavam localizadas nos shoppings centers, e 11,1\% eram cinemas de rua. Em 2011, o público total de cinema no Brasil foi da ordem de 112.6 milhões, em 2017 o público total foi de 181,2 milhões, crescimento de $60 \%$ em sete anos, elevação de $8.5 \%$ ao ano. Ainda em 2009, a renda total obtida por meio da venda de ingressos nos cinemas brasileiros foi de R 969.7 milhões, em 2017 a renda alcançou o montante de R\$ 2.7 bilhões. O total de títulos lançados em 2007 (incluindo documentários, animações e longas-metragens brasileiros e estrangeiros) foi 307, ao passo que em 2017 foram 460 títulos.

$\mathrm{O}$ vetor cinema de tela grande teve todos os seus elos dinamizados e densificados, mas o crescimento maior ocorreu na cadeia de conteúdos cinematográficos brasileiros (animação, documentários e longasmetragens). Alguns dados comprovam essa afirmação. $\mathrm{O}$ total de filmes brasileiros lançados em 2009 foi 84, em 2017 foram 158, um crescimento de $90 \%$, bastante significativo em apenas sete anos. A participação do público consumidor de filmes brasileiros oscilou entre 14,3\% e 9,6\%, alinhavando uma participação bastante contundente nos anos 2010 (19,1\%), 2013 (18,6\%) e 2016 (16,5\%), perfazendo uma média de participação de 14.05\% A princípio, parece um percentual pífio, mas, a rigor, como demonstramos em outra oportunidade (ALVES, 2017), há uma competição atroz por parte dos grandes conglomerados norte-americanos pelo domínio dos mercados nacionais emergentes, como o brasileiro. Por exemplo, no elo distribuição, em 2010, 82\% dos conteúdos brasileiros (longas-metragens de ficção, animação e documentários) foram distribuídos por estúdios norteamericanos, como Disney e Fox. Esse percentual se inverteu inteiramente 
em 2017. As empresas nacionais de distribuição, como a Paris Filmes, distribuíram $86 \%$ dos conteúdos nacionais. Esses resultados somente foram alcançados devido ao impacto dos recursos financeiros disponibilizados pelo Fundo Setorial do Audiovisual (FSA) para as empresas brasileiras de produção, distribuição e exibição, que, paulatinamente, converteu a ANCINE e o BNDES, principal gestor financeiro do FSA, em verdadeiros agentes estatais de mercado (ALVES, 2017). No entanto, o aspecto mais contundente foi a elevação geral na venda de ingressos.

Gráfico 2 - Público total em salas de cinema (2009 a 2017)

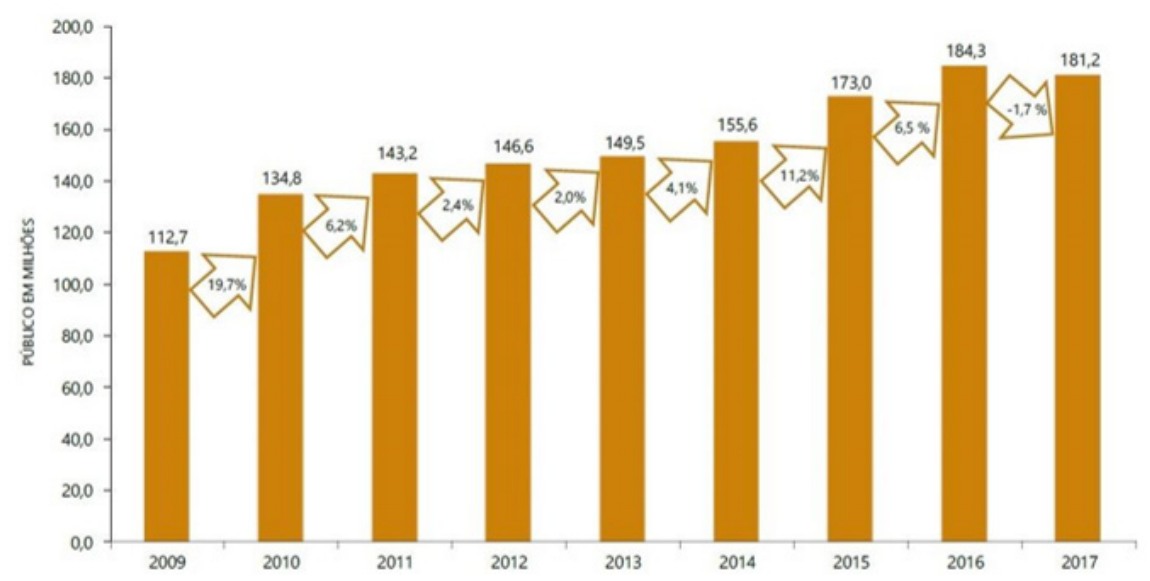

Fonte: ANCINE (2017).

\section{0 vetor internet (os dispositivos digitais móveis e fixos)}

Não se pode confundir o consumo dos serviços digitais culturais das famílias com o e-commerce. A compra de conteúdos de arte, cultura e entretenimento por meio de suportes digitais (móveis e fixos) é bastante distinta da prática do e-commerce. Esse último é uma atividade que consiste na compra de toda sorte de produtos nos sites e plataformas on-line das corporações, cujo advento remonta à expansão da internet, em meados da década de 1990. A rigor, o e-commerce é uma prática comercial específica realizada nas esferas da comunicação e da informação digital, bastante distinta da prática do consumo dos bens culturais e dos serviços culturais. Também não se pode confundir as atividades de comunicação e informação realizadas no 
ambiente digital com os serviços culturais-digitais propriamente ditos. É preciso assinalar, como demonstrado na Figura 2, que no escopo geral do capitalismo cultural-digital, de seus diversos mercados, dos vetores que integram alguns desses mercados e das cadeias que existem nos limites de alguns desses vetores, existem diversas atividades e serviços de comunicação e informação, mas essas não se confundem com os conteúdos dos bens culturais (off-line) e dos serviços culturais (on-line). Embora sejam muito relevantes, essas atividades e serviços são tangenciais, não ficando sob a responsabilidade direta de um dos agentes estruturais centrais dos mercados culturais-digitais.

Figura 2 - Esferas de comunicação, informação, bens culturais e serviços culturais-digitais

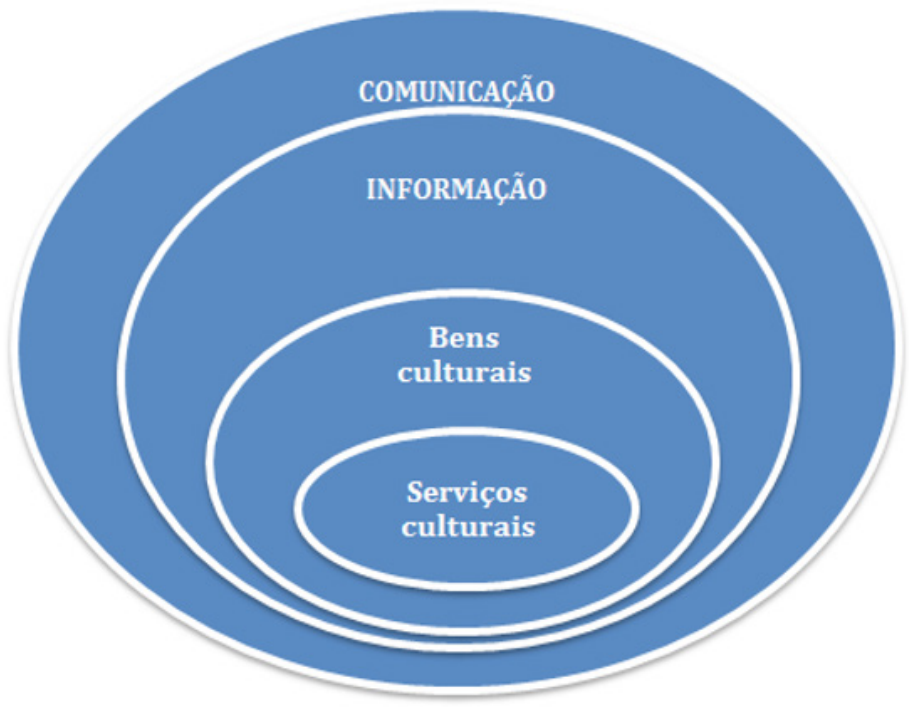

Fonte: Elaboração dos autores.

De certo, não é possível operar analiticamente com a tipologia do capitalismo cultural-digital sem levar em conta as estreitas interfaces com as esferas comunicacionais e informacionais. A rigor, um dos eixos decisivos do processo de digitalização do simbólico concerne à consolidação da internet 2.0, irrigada incessantemente pelo fluxo global de comunicações e informações que circulam e são distribuídas pelas redes sociais digitais - Facebook, Instagram, Whatsapp, Twitter, entre outros. Os serviços culturais e os conteúdos digitais não podem prescindir dos processos de comunicação 
e informação, especialmente digitais. Notadamente, os conteúdos audiovisuais (séries, filmes, documentários, games e animações) têm parte dos seus conteúdos circulados e distribuídos pelas redes sociais digitais. E mais, as empresas e plataformas on-demand que operam via streaming (Netflix, Amazon, Disney, Spotify, Deezer, Twist, etc.) realizam grande parte das suas atividades publicitárias e das formas de indução ao consumo por meio das redes sociais digitais e, portanto, lançam mão de diversos instrumentos de comunicação e informação publicitária, principalmente por meio dos smartphones. Todavia, como assinalado antes, as atividades de comunicação e informação não se confundem com os serviços culturaisdigitais.

Em face desses aspectos, no limite, poderíamos abarcar todas essas interfaces e suas múltiplas clivagens lançando mão do conceito/tipologia de capitalismo cultural-digital-comunicacional-informacional. No entanto, ao fazê-lo, perderíamos determinadas especificidades, deixando escapar, com a precisão necessária, o grau de digitalização, integração digital e inovação tecnológica dos mercados culturais-digitais, como destaca a Figura 1. Ora, mas não estamos aqui sustentando a necessidade de revisão metodológica por parte do IBGE e a necessária inserção dos serviços comunicacionais e informacionais nos gastos orçamentários das famílias brasileiras com cultura? Diante de tal imperativo metodológico, não seria esse o momento de lançar mão de uma categoria que capturasse também as esferas comunicacionais e informacionais? Sim, essa é uma possibilidade, mas, por ora, essa escolha resultaria em muitas imprecisões. Para a adoção dessa nova metodologia, é preciso, antes de tudo, a realização de um mapeamento rigoroso dos mercados estritamente culturais-digitais que compõem o capitalismo cultural-digital. Diante desse mapeamento empíricodescritivo, será possível incorporar itens precisos nos instrumentos de coleta da Pesquisa Nacional por Amostra de Domicílios (IBGE, 2017a) e da Pesquisa por Orçamento Familiar (IBGE, 2011), tais quais o gasto orçamentário da família com o pagamento mensal de assinaturas junto a empresas/ plataformas, como Netflix e Spotify, e, ainda, o valor dispendido para o pagamento das mensalidades pré-pagas com a telefonia móvel e o custo dessa assinatura para o acesso a conteúdos digitais regulares. Ou seja, nos instrumentos de coleta presentes nessas grandes amostras nacionais, os questionários tencionariam capturar tais práticas e os seus dispêndios específicos. Feito esse procedimento, teríamos muito mais clareza dos sistemas de interfaces que estamos buscando capturar aqui. 
De acordo com a Pesquisa PNAD/IBGE, em 2017, 64\% da população brasileira utilizava regularmente a internet. Desse contingente, a esmagadora maioria acessa a rede mundial de computadores por meio do telefone celular, o smartphone. Em 2013, do total de usuários da internet no Brasil, 53,6\% acessavam a internet através do smartphone, esse percentual subiu para 92,1\% em 2015. Como evidencia o Gráfico 3, o uso do smartphone para acessar a internet aumentou em todas as grandes regiões brasileiras entre 2013 e 2015. No final do segundo semestre de 2017, o Brasil possuía 242 milhões de linhas de celular ativas, quantidade bastante superior à população brasileira, estimada em 204 milhões àquela altura. Em 2015, o Brasil possuía a maior média global diária de horas acessando a internet por meio do PC, tablet e smartphones: cinco horas e vinte e seis minutos.

Gráfico 3 - Percentual de domicílios com utilização da Internet, no total de domicílios particulares permanentes com utilização da Internet, por Grandes Regiões, segundo o tipo de equipamento utilizado para acessar a Internet - 2015

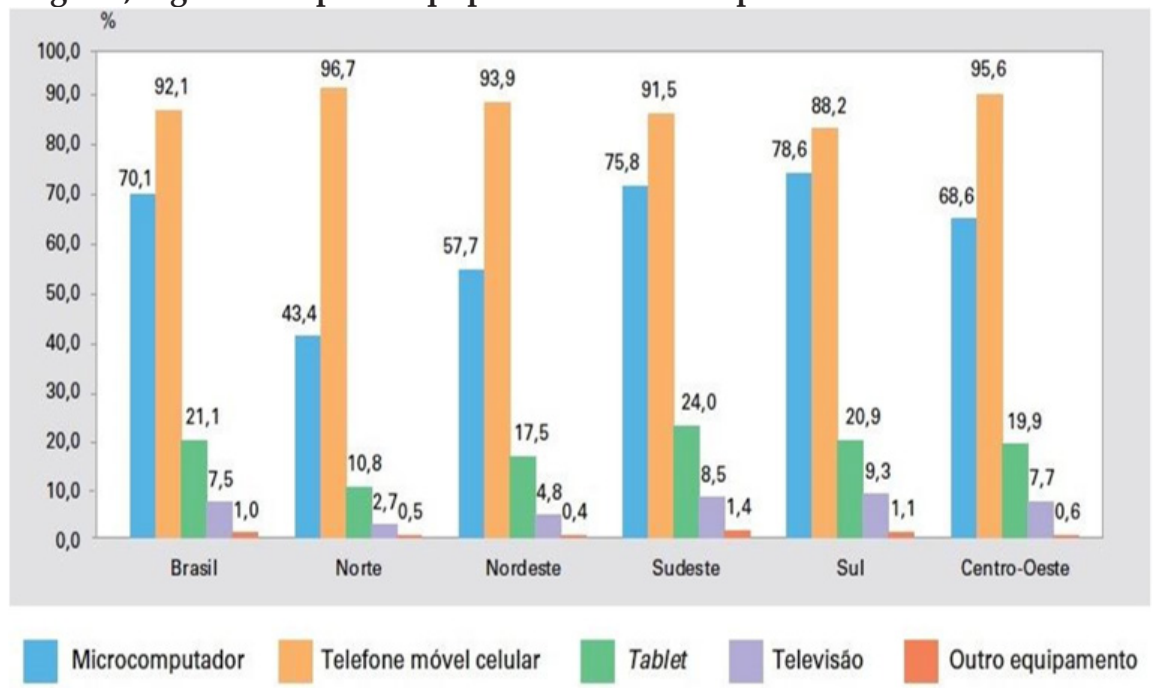

Fonte: IBGE (2017a).

Mesmo diante da redução da renda e do recuo do consumo das famílias entre os anos de 2014 e 2016, o Brasil continuou ocupando a quarta posição entre os países que mais venderam smartphones em todo o mundo. De todo os aparelhos comercializados em 2016, 43,5 milhões foram smartphones, o que representou cerca de $90 \%$, registrando um recuo de $7,3 \%$ no total de aparelhos vendidos em comparação com 2015. De outro lado, o último 
trimestre de 2016 registrou uma elevação de 16\% na venda de smartphones em comparação com o mesmo período de 2015. Durante esse período foram comercializados 13,8 milhões de novos aparelhos, dos quais 12,5 milhões foram smartphones (TELEBRASIL, 2018).

Em 2015, do total de usuários da internet no Brasil, 53\% utilizaram exclusivamente o smartphone para consumir vídeos, programas, filmes, séries, fornecidos por empresas como a norte-americana Netflix. Por sua vez, $47 \%$ dos usuários de internet no Brasil acessaram a rede exclusivamente pelo aparelho celular, para ouvir conteúdos musicais on-line, fornecidos por empresas como Deezer, Spotify e Youtube. Em 2014, do total de usuários que utilizavam exclusivamente o smartphone para acessar a internet, 57\% o fizeram para ouvir música, em 2016 esse percentual subiu para 66\%. Em 2014, desse mesmo contingente de usuários que utilizaram exclusivamente o smartphone para acessar à internet, $42 \%$ o fizeram para assistir a vídeos, em 2016 esse percentual aumentou para 62\%, um aumento de quase 50\% em apenas dois anos (Gráfico 4). 
Gráfico 4 - Usuários de telefone celular, por atividades realizadas no celeular nos últimos três meses (2014-2016). Total de pessoas que utilizaram o telefone celeular $(\%)$

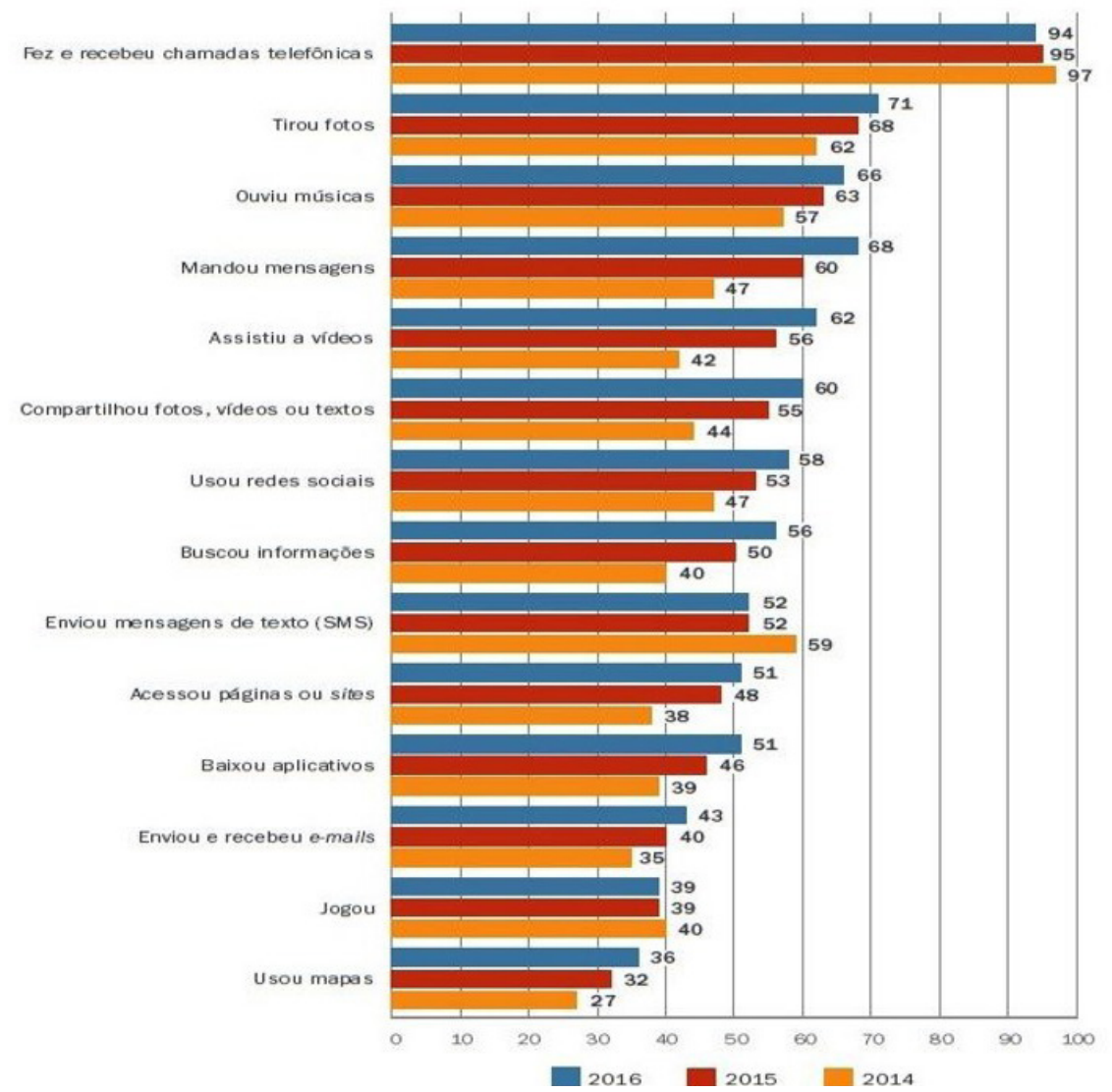

Fonte: COMITÊ GESTOR DE INTERNET NO BRASIL (2016).

As práticas de consumo simbólico através dos serviços digitais com o uso regular do smartphone obtiveram crescimento em todos os segmentos e linguagens entre 2014 e 2015. De acordo com o Sebrae, em 2014, 57\% dos usuários ouviram música, ao passo que em 2015 esse percentual subiu para 63\%. Em 2014, 42\% assistiram a vídeos, ao passo que em 2015 esse percentual alcançou $56 \%$ dos usuários. Esses dados são confirmados por outras fontes, como a UNESCO (2017), que evidenciam um crescimento significativo dos serviços de streaming entre 2014 e 2015. Do total de usuários de internet, em 2014, 58\% assistiram a vídeos, filmes, séries e programas por meio do streaming, e 57\% ouviram música também por meio desses serviços. Em 2015, esses percentuais se elevaram, alcançando $64 \%$ no primeiro item e 
$59 \%$ no segundo. Esses dados se invertem quando se referem aos mesmos consumos através dos serviços de download. Em 2014, 29\% baixaram ou fizeram download de filmes e $51 \%$ baixaram ou fizeram download de músicas. Em 2015, o primeiro item recuou para $23 \%$ e o segundo item para $48 \%$ (UNESCO, 2017).

A expansão da tecnologia $3 \mathrm{G}$ e $4 \mathrm{G}$ aliada ao aumento da conectividade e à elevação do consumo dos serviços de streaming por meio dos pacotes pós-pagos de telefonia pressionaram a criação de produtos de serviços que buscam aproximar os consumidores das operadoras de telefonia móvel. De acordo com o levantamento da Convergência Digital, nos anos de 2015 e 2016, aumentou em 50\% a procura por aplicativos como "Minha Oi, "Minha Tim", "Meu Vivo" e "Meu Claro". Esses aplicativos integram os serviços de valor agregado, ofertados pelas operadoras de telefonia móvel e fixa através dos serviços pós-pagos. A busca por esses serviços cresceu 68\% no ano de 2017, em comparação com 2016. De acordo com o Google, no seu sistema de busca, a procura por planos e pacotes pós-pagos cresceu $64 \%$ entre 2016 e 2017, ao passo que a busca pelos pacotes pré-pagos cresceu apenas $22 \%$. De acordo com o Comitê Gestor de Internet no Brasil (CGI), em 2008 apenas $8 \%$ do total de usuários de celular no Brasil possuíam pacotes de assinatura mensal pós-pagos, em 2016, oito anos depois, esse percentual subiu para $23 \%$.

O aumento dos pacotes pós-pagos e a intensificação do consumo dos serviços culturais-digitais por parte das famílias se inscrevem no movimento mais amplo de recrudescimento e diferenciação dos usos da internet no Brasil. No entanto, esse movimento vem acompanhado da reprodução dos processos assimétricos e extremamente desiguais de distribuição dos recursos econômicos, simbólicos e educacionais existentes na sociedade brasileira. De acordo com a pesquisa encomendada pela SECOM, nada menos do que $62 \%$ dos estratos familiares que recebem entre $\mathrm{R} \$ 1.670$ e $\mathrm{R} \$$ 4.400 disseram acessar a internet todos os dias da semana; e $77 \%$ dos estratos familiares que recebem entre $\mathrm{R} \$ 4.400$ e 8.800 disseram que também acessam a internet todos os sete dias da semana, ininterruptamente. Por outro lado, $61 \%$ do estrato com renda familiar de até $\mathrm{R} \$ 880$ disse não acessar/navegar em dia algum. Esse percentual diminui de forma acentuada assim que se eleva a remuneração do estrato familiar. No caso dos domicílios que recebem entre $R \$ 880$ e $R$ \$1.760, 42\% disseram que não navegam/acessam de modo algum. Os não usuários, portanto, representam um contingente bastante significativo (Gráfico 5). 


\section{Gráfico 5 - Quantos dias da semana, de segunda a domingo, o(a) sr.(a) utiliza a}

internet?

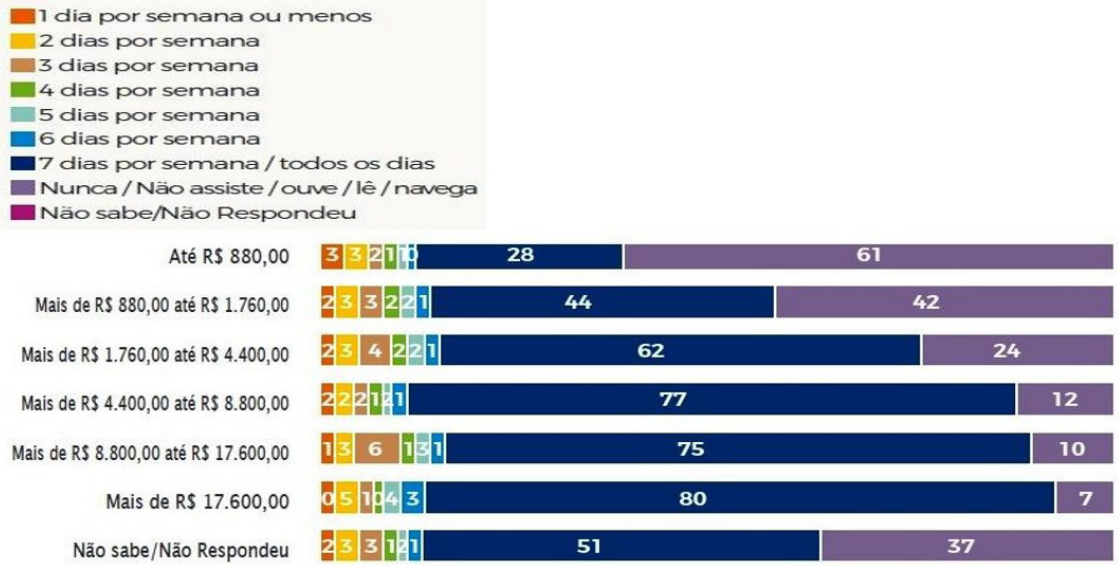

Fonte: SECOM (2017).

Perguntada sobre a intensidade do uso diário da internet, a amostra entrevistada pela pesquisa da SECOM evidencia novamente o destaque sobre os estratos de maior renda familiar. $29 \%$ do estrato com renda familiar entre $\mathrm{R} \$ 1.760$ e $\mathrm{R} \$ 4.400$ disse que acessa a internet mais de 300 minutos por dia (cinco horas); $33 \%$ do estrato familiar com renda entre $\mathrm{R} \$ 4.400$ e $\mathrm{R} \$$ 8.800 disse também permanecer mais de 300 minutos acessando a internet diariamente. Em 2013, 75,7\% do total de usuários de internet situados na faixa etária dos 15 aos 17 anos acessavam regularmente a internet; em 2015, esse percentual subiu para 82\%. Ainda em 2013, 73,8\% dos usuários de internet que pertenciam à faixa etária dos 18 ou 19 anos acessavam a internet regularmente; ao passo que, em 2015, esse percentual se elevou para $82,9 \%$. Do mesmo modo, em 2013, 70,5\% dos usuários de internet acessavam a rede regularmente; em 2015, esse percentual subiu para 80,7\%. Essas são as faixas etárias que mais acessam a internet no Brasil. Aliada à variável faixa etária, a variável escolaridade revela uma componente relevante da concentração do uso da internet e do consumo dos serviços culturaisdigitais das famílias no Brasil. Em 2013, 72,8\% dos usuários da internet que pertenciam ao grupo de 11 a 14 anos de estudos acessavam a internet regularmente; ao passo que, em 2015, esse percentual subiu para $80,5 \%$. Do mesmo modo, em 2013, 89,8\% dos usuários de internet pertencentes ao grupo de estudos com mais de 15 anos de estudos acessavam regularmente a internet; em 2015, esse percentual alcançou 92,3\%. Todas essas variáveis são dependentes da variável renda. A variável sociológica renda é o ponto 
de culminância de um conjunto multifacetado de fatores, cuja gênese remonta ao que Hasembalg definiu como ciclo cumulativo de desvantagem dos estratos brasileiros mais pobres, em sua maioria negra e jovem.

Gráfico 6 - Percentual de pessoas que utilizam a internet, no período de referência dos últimos três meses, na população de 10 anos ou mais de idade por classe de rendimento mensal domiciliar per capita - Brasil - 2013-2015

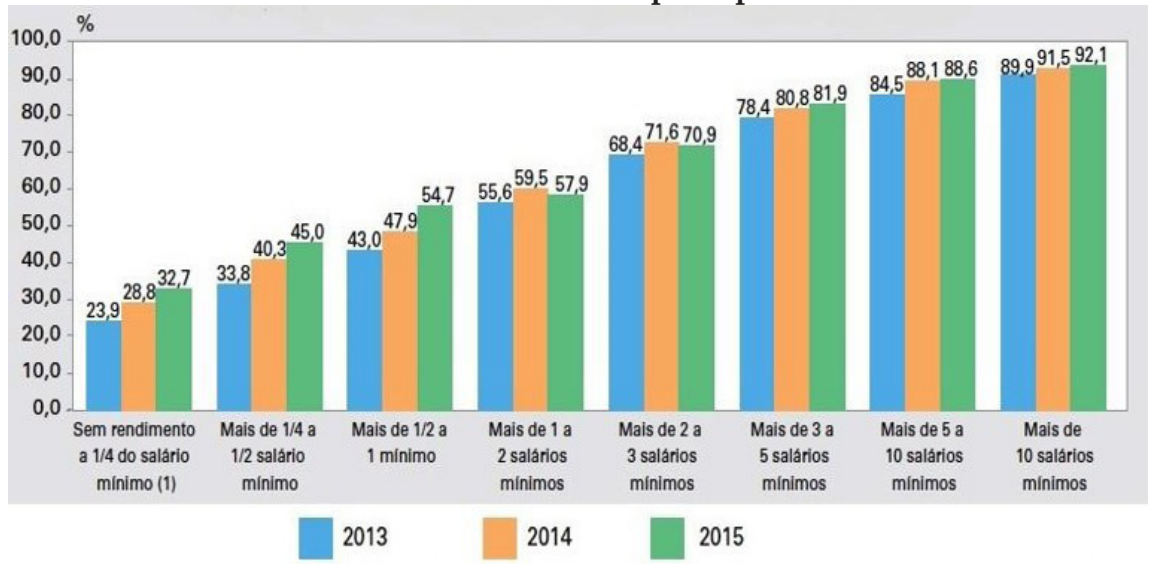

Fonte: IBGE (2017a).

As variáveis renda e escolaridade são decisivas e demonstram com clareza as assimetrias entre as clivagens de classes que consomem os serviços culturais-digitais. O Gráfico 6 demonstra que a primeira tem sido decisiva, revelando, junto com o Gráfico 5, uma elevada concentração de usuários e consumidores entre os estratos domiciliares com mais renda.

Embora, conforme o Gráfico 6, secundado pelo Gráfico 5, exista uma severa desigualdade entre os estratos de renda quanto ao acesso regular à internet, entre os anos de 2013 e 2015, o crescimento relativo mais elevado ocorreu nos estratos domiciliares de menor renda. Em 2013, 23,9\% dos estratos domiciliares não possuíam rendimento ou seu rendimento era de 1/4 do salário mínimo (cerca de R\$ 169.5); em 2015, esse percentual se elevou para $32,7 \%$. O crescimento mais significativo ocorreu no estrato de renda domiciliar seguinte. Em 2013, 33,8\% dos domicílios com renda mensal entre $1 / 4$ e 1/2 salário mínimo acessaram regularmente a internet, esse percentual subiu para $45,0 \%$ em 2015 , um crescimento de $35 \%$ em dois anos. No estrato domiciliar seguinte, que aufere uma renda de 1/2 a um salário mínimo, em 2013, 43,0\% dos seus membros acessavam regularmente a internet, percentual que subiu para 54,7\% em 2015. 
Os dados apresentados no Gráfico 6 se coadunam com outra fonte, também realizada pelo IBGE. De acordo com a Síntese de Indicadores Sociais (IBGE, 2017b), mesmo a população brasileira mais pobre, que, por domicílio, recebe até 5,5 dólares por dia (o que corresponde a apenas $\mathrm{R} \$ 523,00^{3}$ por mês), acessava a internet regularmente por meio dos dispositivos digitais móveis, principalmente celulares. Os dados apresentados evidenciam uma severa concentração de usuários nos estratos superiores de domicílios com renda elevada. Por outro lado, mesmo os $46 \%$ dos domicílios mais pobres, que obtêm uma renda mensal de apenas R\$ 523,00, acessam a internet regularmente por meio dos dispositivos móveis. Estamos, pois, diante de dois movimentos aparentemente contraditórios. De um lado, temos uma elevada concentração, desigualdade e exclusão no uso da internet, e, de outro, uma elevação rápida do acesso por parte dos domicílios mais pobres. Podemos ousar arriscar dizer que esse fenômeno ocorre muito em razão de dois processos. O primeiro se deve à elevada concentração de renda e imensa desigualdade brasileira, obedecendo ao padrão secular de manutenção da desigualdade socioeconômica brasileira; o segundo ocorre muito em razão do compartilhamento dos sinais públicos e privados (estabelecimentos abertos e vizinhos) de $w i$-fi, que permite que os estratos pobres das periferias urbanas e dos espaços rurais acessem os conteúdos digitais (notícias, imagens, áudios, mensagens, músicas, etc.), principalmente através das redes sociais digitais. Esses estratos, no entanto, não pertencem às famílias que consomem cotidianamente os conteúdos (filmes, séries, documentários, animação, games, etc.) ofertados através dos serviços culturais-digitais especializados, por meio de assinaturas junto aos pacotes pós-pagos da telefonia móvel no âmbito do vetor internet, principalmente smartphones.

\section{Vetor TV por assinatura}

O vetor do mercado audiovisual TV por assinatura foi um dos que mais cresceram no mundo entre 2007 e 2017. Especialmente no Brasil, esse crescimento foi exponencial. Em 2009, o Brasil possuía 7,5 milhões de assinantes de TV por assinatura, abarcando cerca de 22 milhões de pessoas, uma vez que, de acordo com o IBGE, o Brasil abriga, em média, 3 pessoas por domicílio. Seis anos depois, em 2015, o total de assinantes de TV por

${ }^{3}$ De acordo com a cotação do dólar no final de fevereiro de 2018. 
assinatura subiu para 19,1 milhões, alcançando 60 milhões de pessoas, cerca de $30 \%$ da população brasileira. Ou seja, em seis anos, o contingente de assinaturas dobrou no Brasil. O pináculo desse crescimento ocorreu em 2015, quando a base de assinantes no Brasil alcançou 19,6 milhões de assinaturas domiciliares, alcançando quase 30 milhões de pessoas. Em razão da concentração sócio-histórica das atividades econômicas, da distribuição da renda nacional e também da demasiada concentração das oportunidades profissionais, no final de 2015 a região Sudeste abrigava 42\% da base geral de assinaturas.

\section{Gráfico 7 - Evolução Anual do Número de Assinantes da TV Paga}

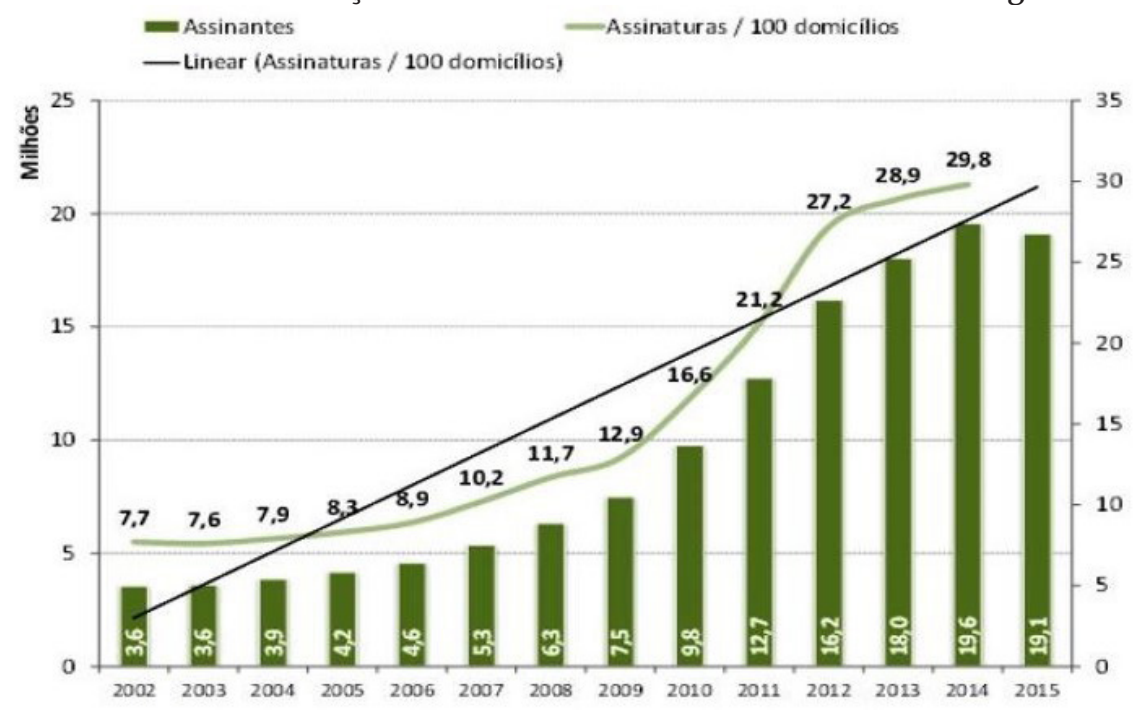

Fonte: ANCINE (2017).

O Gráfico 7 é bastante elucidativo. A primeira constatação é que, até 2007 e 2008, o consumo e os gastos domiciliares das famílias brasileiras com a TV por assinatura eram bastante modestos e extremamente concentrados. Quando o IBGE, através da POF, coletou os gastos orçamentares das famílias brasileiras com cultura, publicado em 2009, e chegou ao percentual de $5 \%$ da renda doméstica mensal, a espiral de crescimento do consumo cultural das famílias estava no seu início, especialmente nos vetores internet (notadamente os smartphones), TV por assinatura e cinema de tela grande. Semelhantemente ao que ocorreu com o vetor de cinema de tela grande, no caso do vetor TV por assinatura também ocorreu o crescimento 
na cadeia interna de conteúdos televisivos brasileiros. No vetor TV por assinatura também há uma clivagem interna entre a cadeia de conteúdos televisivos nacionais e estrangeiros. E também aqui ocorre uma competição encarniçada das grandes companhias, empresas e conglomerados de canais de produção e distribuição norte-americanos pelo domínio de mercados nacionais emergentes, como o brasileiro. Mesmo com a aplicação da Lei 12.485 e dos mecanismos de cota adotados pelo governo brasileiro a partir de 2012, em 2016, 90\% dos conteúdos exibidos na TV por assinatura brasileira foram produzidos e distribuídos por empresas e canais estrangeiros, a maioria esmagadora de origem norte-americana.

Em razão da redução geral da renda e do pronunciado crescimento nas taxas de desemprego entre os anos de 2015 e 2016 e da respectiva intensificação da recessão brasileira, a TV por assinatura sofreu um recuo na sua base nacional de assinantes. Como assinala o Gráfico 8, entre junho de 2015 e junho de 2016, o Brasil perdeu 700 mil assinaturas de TV por assinatura, uma redução de 3,7\% na base total de assinantes.

\section{Gráfico 8 - Evolução mensal do número de assinantes de TV por assinatura de} junho de 2015 a junho de 2016

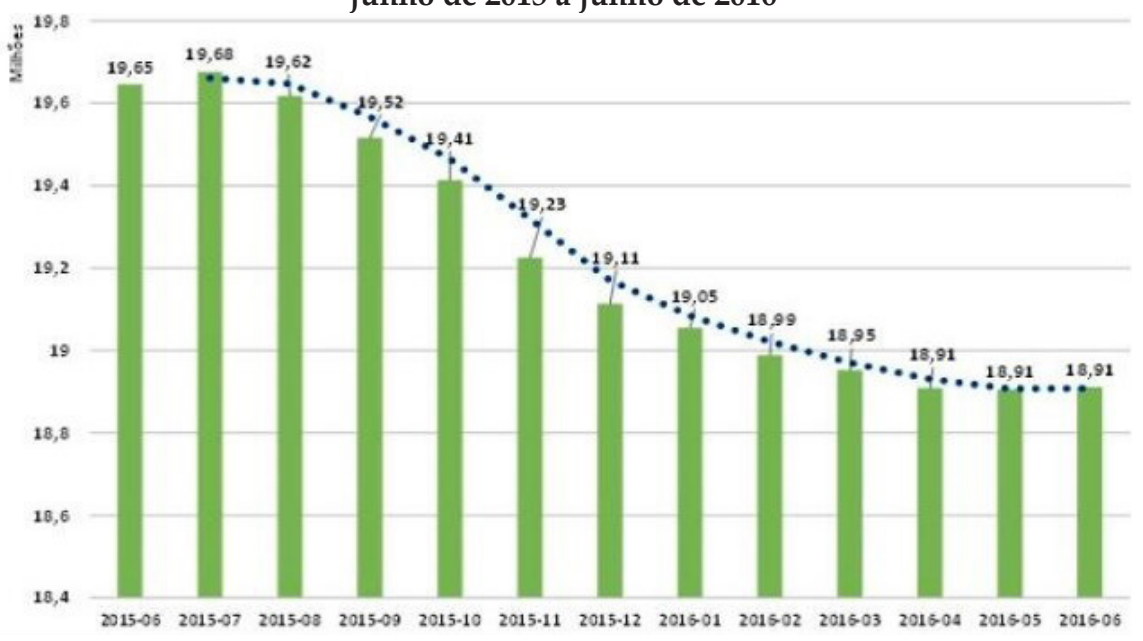

Fonte: ANCINE (2017).

O declínio constatado pelo Gráfico 8, não obstante, pode ser considerado modesto diante da redução geral do consumo das famílias brasileiras registrada nos anos de 2014, 2015 e 2016. Tanto é que, de acordo com o IBGE, entre junho de 2015 e junho de 2016, o volume de serviços prestados 
às famílias brasileiras teve uma redução geral de $5,2 \%$, ao passo que os serviços de telecomunicações - nos quais se inscrevem a TV por assinatura e os pacotes de telefonia pós-pagos junto às operadoras de telefonia móvel - sofreram uma redução menor, 3,2\%. Diante desse aspecto, além da redução geral da renda das famílias entre 2014 e 2016, o que explica, então, a redução das assinaturas no vetor TV por assinatura? São quatro fatores: 1) a redução ocorreu muito mais nos domicílios com rendimentos mensais baixos ou médio-baixos e muito menos nos domicílios com renda média e média alta; 2) a redução foi acomodada pelas empresas de empacotamento e distribuição (NET, SKY, entre outras), que reduziram os valores nominais cobrados pelos diferentes pacotes; 3 ) em face da redução da renda e também da redução dos preços dos pacotes, muitas famílias mudaram de planos e/ ou permaneceram em planos com novos descontos; 4) por fim, podemos assinalar, à luz dos dados mobilizados e minerados antes, que entre $20 \%$ e $30 \%$ das famílias migraram para os serviços de acesso aos conteúdos ofertados via os serviços de streaming, como Netflx e GloboPlay.

De acordo com a ANCINE, a maioria das operadoras e empacotadoras do vetor TV por assinatura reduziram os preços dos seus pacotes básicos e premium, essa última modalidade oferece a maioria dos canais especializados em longas-metragens, séries, documentários e animação. De outro lado, também estenderam as possibilidades dos pacotes básicos, permitindo a utilização de novos e mais canais, como os de cinema. Como pode ser constatado pelo Gráfico 9, esses aspectos resultaram muito mais numa redução dos pacotes premium e muito menos numa redução geral na base de assinantes.

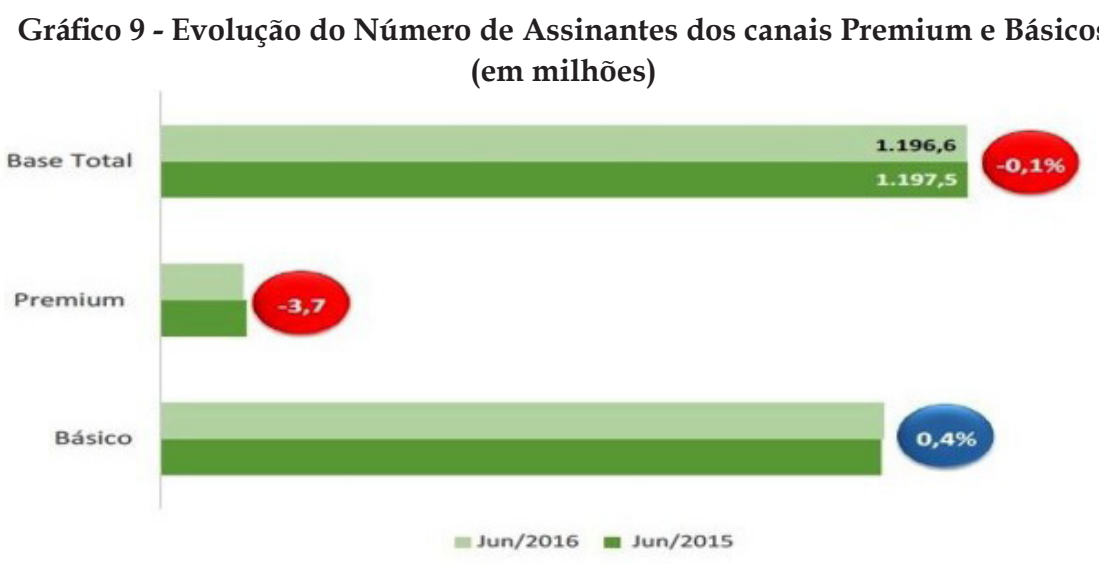

Fonte: ANCINE (2017). 


\section{Considerações finais}

Diante dos dados coligidos e tratados, podemos sustentar que, de fato, a metodologia do cálculo de aferição dos gastos das famílias brasileiras com cultura deve ser alterada, reclamando uma atualização. Diante da expansão dos gastos com os pacotes de telefonia móvel, especialmente na modalidade pós-pago, que permite o consumo dos conteúdos dos serviços culturais-digitais (filmes, séries, livros, documentários, games e músicas) ofertados pelas plataformas on-demand, impõe-se a incorporação desses gastos na rubrica cultura, mas não com a tipologia evasiva e imprecisa de gastos orçamentários com serviços de comunicação e informação por parte das famílias. Como sustentamos, por meio da visada sociológica que perscruta e objetiva o capitalismo cultural-digital, é preciso tipologias conceituais claras e precisas para produzir, a partir de instrumentos claros, as métricas exatas que permitam elucidar a intensa transição que marca os mercados culturais em direção aos mercados culturais-digitais, cada vez mais povoados pelos serviços culturais-digitais.

\section{Referências}

ALVES, Elder P. M.

(2017). 0 capitalismo cultural-digital: investimento cultural-digital versus incentivos fiscais. São Paulo: Itaú Cultural.

ALVES, Elder P. M.

(2016). A expansão do mercado de conteúdos audiovisuais brasileiros: a centralidade dos agentes estatais de mercado - o FSA, a ANCINE e o BNDES. Revista Cadernos do CRH, Salvador, Universidade Federal da Bahia.

ALVES, Elder P. $M$

(2019). A digitalização do simbólico e o capitalismo cultural-digital: a expansão dos serviços culturais-digitais no Brasil. Sociedade \& Estado. Brasília, Universidade de Brasília.

ANCINE.

(2016). Anuário estatístico do cinema brasileiro. Rio de Janeiro.
ANCINE.

(2018). Informe preliminar anual de 2017 sobre o cinema brasileiro. Rio de Janeiro.

ANCINE.

(2017). Estudo anual sobre o emprego no setor audiovisual. Rio de Janeiro.

ANCINE.

(2017). Impacto da crise econômico nos mercados de programação e empacotamento da TV por assinatura no Brasil. Rio de Janeiro.

MARTEL, Frederic.

(2013). Mainstream: a guerra global das mídias e das culturas. Rio de Janeiro: Civilização Brasileira.

BELL, Daniel.

(1977). Advento da sociedade pós-industrial: uma tentativa de previsão social. São Paulo, Cultrix. 
BENJAMIN, Walter.

(2007). Passagens. Belo Horizonte: Editora da UFMG.

CASTELLS, Manuel.

(2010). A sociedade em rede. São Paulo: Paz e Terra.

COMITÊ GESTOR DE INTERNET NO BRASIL.

(2016). Pesquisa sobre o uso das tecnologias da informação nos domicílios brasileiros. São Paulo.

DEEZER.

(2017). Digital Music Report. Rio de Janeiro.

IBGE.

(2017a). Pesquisa nacional por amostras de domicílios acerca do acesso à internet e à televisão e posse de telefone móvel celular para uso pessoal. Brasília.

IBGE.

(2011). Pesquisa de orçamentos familiares 2008-2009. Brasília

IBGE.

(2017b). Sintese de Indicadores Sociais: uma análise das condições de vida da população brasileira. Brasília.
MARTEL, Frederic.

(2013). Mainstream: a guerra global das mídias e das culturas. Rio de Janeiro: Civilização Brasileira.

\section{SEBRAE.}

(2018). Sistema de indicadores econômicos. Brasília.

SECOM.

(2017). Pesquisa nacional sobre consumo de mídia e tempo livre. Brasília.

TELEBRASIL.

(2018). Painel Telebrasil 2018. Brasília.

UNESCO.

(2017). Pesquisa cultura e tecnologias no Brasil. Brasília.

VOGELSTEIN, Nielson.

(2014). Briga de Cachorro grande: como a Apple e o Google foram à guerra e começaram uma revolução. São Paulo: Intrínseca.

\section{Recebido em}

março de 2019

\section{Aprovado em}

novembro de 2019 